Fertility in middle age

\title{
BIOLOGICAL AND SOCIAL INTERACTIONS IN THE DETERMINATION OF LATE FERTILITY
}

\author{
R. H. GRAY \\ Special Programme of Research in Human Reproduction, World Health \\ Organization, Geneva
}

Introduction: fertility prior to the menopause

The biological and social factors which may interact to determine the level and pattern of fertility during the last decades of the reproductive life are complex, and because of the paucity of data, the mechanisms regulating fertility at late ages must in part remain speculative. This review focuses on two major questions. First, why is there a decline of fertility prior to the menopause? Second, why does reproduction cease at the menopause and what factors influence the age at which this occurs?

Demographic studies have shown that there is a marked decline of fertility with age, especially after the mid-30s. In many societies the fall in birth rates at later ages is due to deliberate fertility control by the use of contraception, abortion or in some cases sexual abstinence. Such deliberate control can mask or overwhelm any interactions between biological and other social factors which might otherwise determine fertility during middle age, and to assess the effects of these latter factors, it is necessary to examine reproductive patterns in selected societies which do not practice deliberate fertility regulation. The French demographer, Louis Henry, has defined reproduction in the absence of deliberate fertility control as 'natural fertility', and has analysed data from historical European populations and from a number of developing countries during the 20th century in order to illustrate the pattern of reproduction under conditions of 'natural fertility' (Henry, 1961). Some examples of marital fertility rates by age in populations with 'natural fertility' are shown in Fig. 1.

Regardless of the level of fertility during the reproductive years, there is, in all populations, a marked decrease in fertility during the fourth and fifth decades of life, and the shape of the fertility distribution at older ages follows a remarkably similar pattern in the different populations (Fig. 1). In particular, fertility in the 40 44 year age group is between 40 and 50\% lower than in the 35-39 year age group. The decline of fertility with age is such a consistent feature of societies with 'natural fertility' that a more rapid decline in birth rates has been used as an index of voluntary fertility control (Coale \& Trussel, 1974).

The shape of the fertility curve gives an indication of how rapidly fertility declines with age, but it does not directly provide information on the average age at 


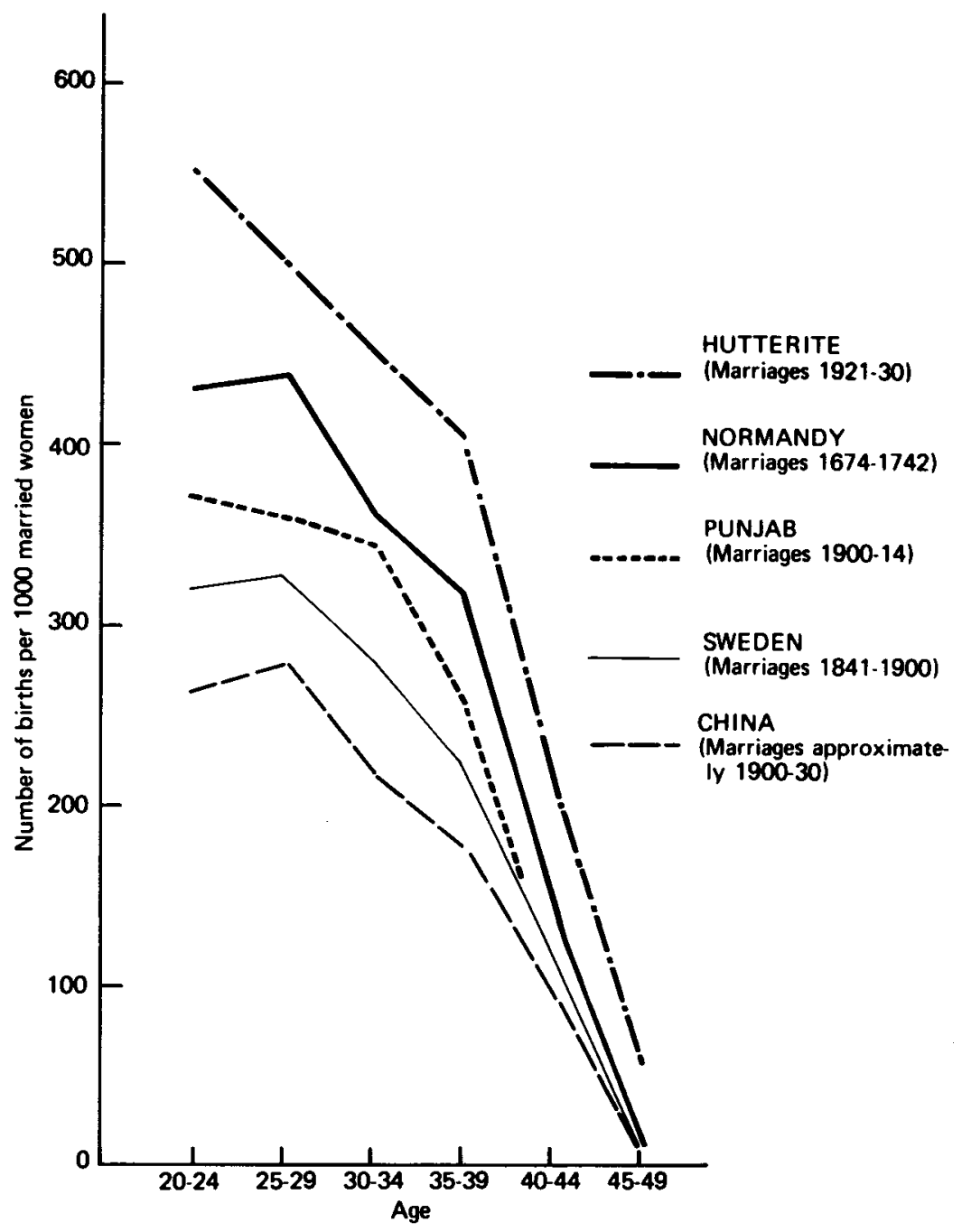

Fig. 1. Age-specific marital fertility for selected populations. Sources: Henry, 1961; Leridon, 1975; Barclay et al., 1976.

which reproduction ceases in a population. Two demographic indices have been used to assess this latter issue: these are the mean age at which women bear their last child, and the age-specific incidence of sterility.

The mean age at last childbirth in a number of historical European populations experiencing 'natural fertility' is estimated to be around 40 years, and it is remarkable how consistently this observation has been reported (Henry, 1961; Knodel, 1978). There are few data available from 20th century populations, but it is noteworthy that among the Hutterites of North America, who have one of the highest levels of fertility ever recorded, the mean age at last confinement is 40.9 years (Tietze, 1957). In contrast, among poorly nourished women in New Guinea 
the mean age at last confinement has been estimated to be between 36.3 and 37.3 years (Scragg, 1973).

The onset of sterility with increasing age is difficult to measure using demographic techniques since it is impossible, on a population basis, to differentiate between those women who are physiologically sterile and those women who are potentially fertile but have reduced fecundity. Despite this and other technical difficulties, it is clear from many studies that the proportion of women who are sterile increases with age in all populations, and the median age at sterility is generally estimated to be around 40 years (Henry, 1961; Pittenger, 1973; Leridon, 1975). Pittenger (1973) using data from a variety of populations with 'natural fertility' has derived an aggregate estimate of the proportion of women sterile by age, and the curve of the age-specific incidence of sterility is shown in Fig. 2.

The age at menopause has been studied extensively, and recent surveys have shown that the median age at menopause in industrialized populations lies within a narrow range between 51.4 years in the Netherlands and 49.8 years in the USA (Gray, 1976). There are only a limited number of reliable studies from developing countries, but the data suggest that the median age at menopause is lower than that observed in industrialized countries, and the range considerably wider. The median age at menopause varies from 49.7 years amongst the Bantu in South Africa (Frere, 1971) to around 44 years among Punjabi women (Wyon, Finner \& Gordon, 1966) and poorly nourished New Guinean women (Scragg, 1973, calculated on augmented data by J. Barrett and R. H. Gray), and around 43 years in some populations of sub-Saharan Africa (Retel-Laurentin, unpublished paper presented at the INED/IUSSP Seminar on Natural Fertility, Paris, 1977). The proportions of women menopausal by age in selected industrialized and nonindustrialized countries are shown in Fig. 2.

A comparison of the age-specific curves of the proportions sterile and postmenopausal (Fig. 2) shows that in developed countries, the median age of sterility antedates the age at menopause by an average of almost 10 years. Even in New Guinea where menopause occurs at a very early age, the curve of the proportions sterile lies to the left of the curves of the proportions menopausal, and the median age at menopause is 4 to 7 years later than the aggregate estimate of the median age of sterility.

Similar differences exist between the age at menopause and the mean age of the mother at the birth of her last child which is generally around 40 years. In the moderately nourished New Guinean population, in which the median age at menopause was 47.3 years, the mean age at last childbirth was around 40 years. In the other, poorly nourished New Guinean population, however, the median age at menopause was approximately 43.6 years, and the mean age at the birth of the last child was estimated to be between $36 \cdot 3$ and 37.3 years (Scragg, 1973).

From these data, it is clear that fertility declines substantially prior to the menopause, and that the median or mean age of terminal reproduction antedates the median age at menopause by up to a decade. These are population-based data and obviously an individual woman may still be at risk of conception until she is post-menopausal, and there have even been occasional reports of pregnancies after the menopause was presumed to have occurred (Talbert, 1968). However, it is 

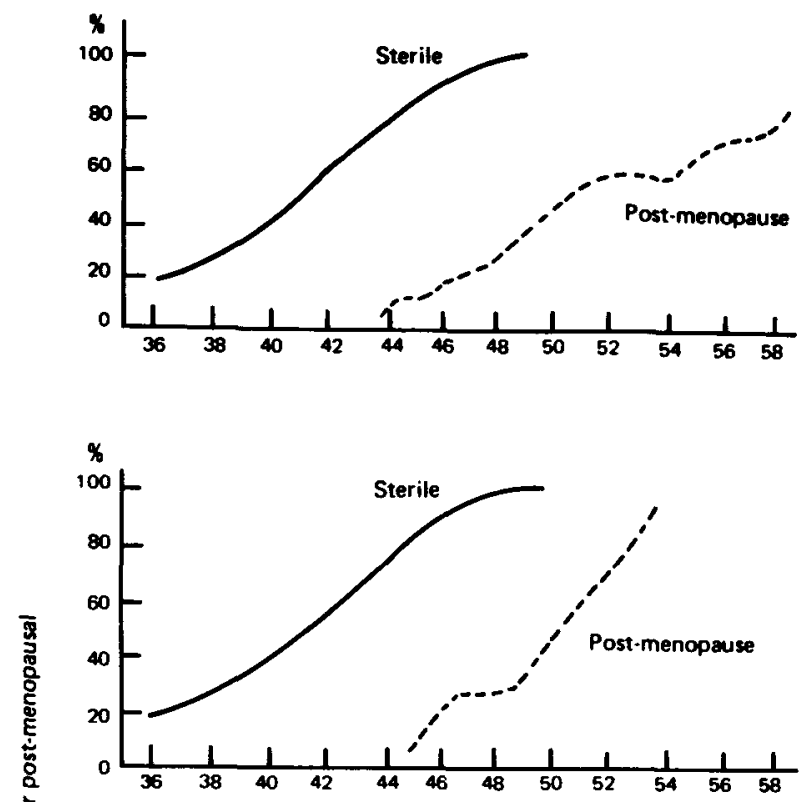

ENGLAND

SOUTH AFRICA

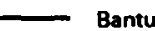

- White
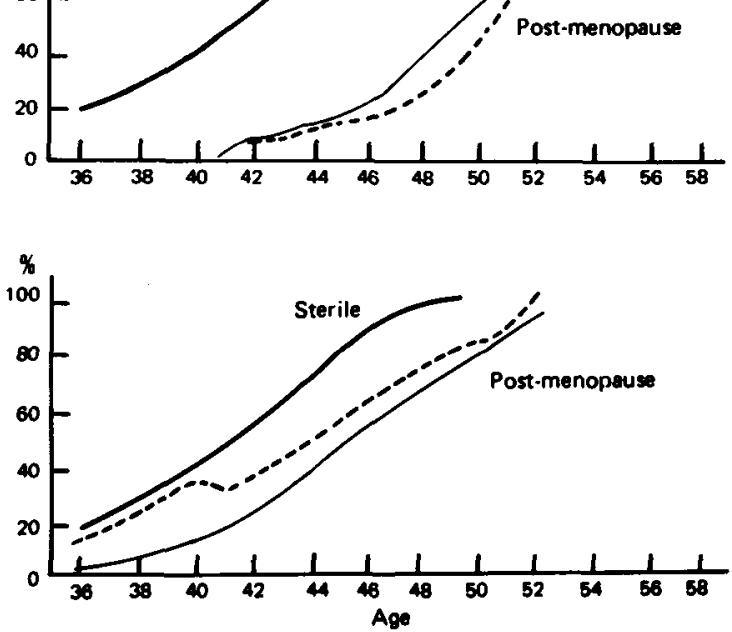

PAPUA NEW GUINEA

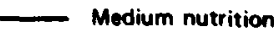

Poor nutrition

Fig. 2. Proportion of women post-menopausal by age for selected populations, compared to the estimated age distribution of sterility in populations with 'natural fertility'. Sources: MacMahon \& Worcester, 1966; Frere, 1971; Thompson, Hart \& Durno, 1973; Scragg, 1973; Pittenger, 1973. 
necessary and important to explain why there is this prolonged period of declining fertility rates prior to the climacterium, and why reproduction ceases after the menopause.

\section{Social and biological factors affecting fertility prior to the menopause}

The biological and social mechanisms which might explain the decline of fertility and termination of reproduction can be divided into those factors which affect the probability of conception, and those which affect the probability that such a conception will result in a live birth.

\section{Factors affecting the probability of conception}

The probability of conception will depend upon the occurrence of ovulation, the viability of the ovum and spermatozoa, and on an act of coitus during the period of the menstrual cycle when fertilization can take place.

There have been a number of studies of changes in the menstrual cycle during the reproductive life, in which the occurrence of ovulation was determined by the measurement of basal body temperature (BBT). A mid-cycle elevation of the BBT is evidence of ovulation, and a monophasic curve with no rise in temperature is generally considered to be indicative of an anovulatory cycle, although it is known that some women with ovulatory cycles fail to have a clear rise in temperature. The interval between ovulation and the onset of the next menstrual period, termed the luteal, hyperthermic or premenstrual phase, is thought to be indicative of the adequacy of corpus luteum function required for the maintenance of early pregnancy. A luteal phase of less than 10 days' duration is considered to be a sign of corpus luteum insufficiency (Doring, 1969).

The frequency of anovulatory cycles, and cycles with a short luteal phase reported in two large series is shown in Table 1. The studies are not fully comparable since the authors employed different age classifications, but the data provide an indication of the range of abnormal cycles during the last two decades

Table 1. The proportion of abnormal menstrual cycles during the later years of the reproductive life

\begin{tabular}{|c|c|c|c|c|c|c|c|}
\hline \multirow[b]{2}{*}{$\begin{array}{c}\text { Age } \\
\text { (years) }\end{array}$} & \multicolumn{3}{|c|}{ Doring's series } & \multicolumn{4}{|c|}{ Vollman's series } \\
\hline & $\begin{array}{l}\text { Anovulatory } \\
\text { cycles } \\
\text { (\%) }\end{array}$ & $\begin{array}{l}\text { Cycles with } \\
\text { a short } \\
\text { luteal phase } \\
(\%)\end{array}$ & $\begin{array}{l}\text { Total } \\
\text { abnormal } \\
\text { cycles } \\
(\%)\end{array}$ & $\begin{array}{c}\text { Approximate } \\
\text { age* } \\
\text { (years) }\end{array}$ & $\begin{array}{l}\text { Anovulatory } \\
\text { cycles } \\
\text { (\%) }\end{array}$ & $\begin{array}{l}\text { Cycles with } \\
\text { a short } \\
\text { luteal phase } \\
(\%)\end{array}$ & $\begin{array}{l}\text { Total } \\
\text { abnormal } \\
\text { cycles } \\
(\%)\end{array}$ \\
\hline $31-35$ & 7 & 9 & 16 & $30-34$ & 3 & 10 & 13 \\
\hline $36-40$ & 3 & 16 & 19 & $35-39$ & 2 & 9 & 11 \\
\hline $41-45$ & 12 & 18 & 30 & $40-44$ & 4 & 12 & 16 \\
\hline $46-50$ & 15 & 36 & 51 & $45+$ & 18 & 12 & 30 \\
\hline
\end{tabular}

Sources: Doring (1969) Table 1; Vollman (1977) Tables 35 and 44.

* The age groups are approximate because the original data are tabulated by gynaecological rather than chronological age. The data were re-tabulated by the present author. 
of the reproductive life. There is an increase in the proportion of abnormal cycles with age. However, in the age group $40-44$ years, $16-30 \%$ of cycles can be considered abnormal yet, as was shown previously, 40 years represents the median age of terminal reproduction and the birth rate declines by $50 \%$ between the age groups 35-39 and 40-44. Other studies of the length of the menstrual cycle suggest that there is an increase in the variability of the cycle pattern after the age of 40 years, and the proportion of short cycles which might be indicative of anovulation increases to about 20\% in the age group 40-44 (Treloar et al., 1967; Chiazze et al., 1968; Vollman, 1977). From these physiological data, it would appear that anovulation or failure of corpus luteum function can explain only a relatively small proportion of the decline in fertility prior to the menopause.

In those societies practising prolonged breast-feeding, post-partum amenorrhoea associated with lactation can be an important determinant of fertility. A number of studies have shown that the duration of amenorrhoea increases with maternal age, and this prolongation of anovulation results in longer birth intervals among older women (Potter, 1963; Jain et al., 1970; Chen et al., 1974).

The observed decline in birth rates could, in part, be due to a reduction in male fertility. Anderson (1975) has analysed Irish census data from 1911 to show a decline of fertility among men over the age of 57.5 years, regardless of the age of the wife or the duration of the marital union. This would suggest that, although reproduction can occur at extremes of age in the male, there is a distinct decline in male fertility after the sixth decade of life. However, the reduction in male fertility is relatively small and, given the usual age difference between spouses, it occurs too late to substantially affect female fertility prior to the menopause.

The changes in male fertility may be due to a reduction in testicular androgen production which occurs after the third decade of life (Bishop, 1970), and endocrine factors could partly explain the age related decline in sexual activity and potency which has been reported in a number of surveys (Kinsey, Pomeroy \& Martin, 1953; Masters \& Johnston, 1966). There is a substantial decline in the frequency of intercourse with age reported in most societies and some examples are given in Table 2. Barrett \& Marshall (1969) have shown that the probability of conception during a menstrual cycle is strongly dependent upon the frequency of intercourse. The monthly probability of conception which is known as fecundability, can vary from approximately $68 \%$ to $17 \%$ depending upon whether coitus takes place once daily or once per week. Theoretical estimates based upon a model fitted to empirical data suggest that a considerable proportion of the apparent decline in fertility with age could be attributable to reductions in the frequency of intercourse (Brass, 1977, personal communication).

In some traditional societies, especially those in which post-partum sexual abstinence is considered normal behaviour, it is not uncommon for older women to abstain totally from intercourse after they have reached either a certain age or number of living children (Caldwell \& Caldwell, 1977). Clearly, such social practices could affect the birth rates at later ages.

\section{Factors affecting the frequency of spontaneous abortion}

Even after fertilization occurs, a high proportion of conceptions will result in 
Table 2. Average frequency of intercourse per week for selected populations

\begin{tabular}{cccccc}
\hline $\begin{array}{c}\text { Age } \\
\text { years }\end{array}$ & British* & $\begin{array}{c}\text { American } \\
\text { White }\end{array}$ & Hindu† & $\begin{array}{c}\text { Sheikh } \\
\text { Muslim }\end{array}$ & $\begin{array}{c}\text { Non-Sheikh } \\
\text { Muslim }{ }^{\dagger}\end{array}$ \\
\hline 19 & 2.47 & 3.7 & 1.5 & 1.7 & 2.3 \\
$20-24$ & 2.10 & 3.0 & 1.9 & 2.4 & 2.6 \\
$25-29$ & 1.72 & 2.6 & 1.8 & 2.4 & 2.7 \\
$30-34$ & 1.33 & 2.3 & 1.1 & 1.8 & 2.1 \\
$35-39$ & 1.37 & 2.0 & 0.7 & 1.4 & 1.5 \\
$40-44$ & 1.7 & 0.2 & 1.0 & 0.8 \\
\hline
\end{tabular}

Sources: * Cartwright (1976) Table 58; † Nag (1972) Table 4.

spontaneous abortions. French \& Bierman (1962) have estimated that $23.7 \%$ of all pregnancies of more than 4 weeks' gestational age result in fetal loss, and James (1970) has augmented these data by additional information from embryological studies to estimate that approximately $49 \%$ of all fertilized ova perish prior to full term delivery. The incidence of spontaneous abortions rises markedly with age, and this age related increase is independent of a woman's previous obstetrical history (Shapiro, Levine \& Abramowicz, 1970; Naylor, 1974; Leridon, 1975). Figure 3 shows the average age-specific incidence of fetal wastage estimated from a series of separate studies (Leridon, 1975).

The mechanisms underlying spontaneous abortions and the age related increase in fetal wastage are unclear, but one major contributory factor is likely to be genetic abnormalities. The majority of spontaneous abortions occur during the first trimester of pregnancy, and in French \& Bierman's (1962) series where all conceptions were of 4 weeks' or more duration at first observation, $75 \%$ of spontaneous fetal losses occurred between the 4th and 12th week of gestation. Cytogenetic studies have shown that in $40-60 \%$ of all first trimester abortions, there is evidence of chromosomal abnormalities, and the majority of these anomalies are autosomal trisomic defects in which an extra chromosome is present (Lazar et al., 1973; Alberman \& Creasy, 1975; Creasy, Crolla \& Alberman, 1976; Wright, 1976).

Trisomic abnormalities arise from the non-dysjunction of chromosomes during the first meiotic division whereby the original oocyte containing 46 chromosomes divides into two daughter cells each containing 23 chromosomes. The first meiotic division, which commences in the fetal ovary, is arrested in late prophase, and not completed until the time of ovulation (McKusick, 1964). In the case of nondysjunction, a chromosome fails to separate leaving an excess of chromosomes in one daughter cell (trisomy) and a deficit in the other (monosomy). The majority of autosomal trisomies and all autosomal monosomic anomalies lead to early spontaneous fetal wastage, and only a small minority of trisomies involving chromosomes 13, 18 and 21 survive to full term delivery and give rise to conditions such as Down's syndrome (Creasy et al., 1976; Wright, 1976).

The frequency of trisomy among spontaneous abortions increases with maternal age, but no such effect can be demonstrated with paternal age (Lazar et al., 1973; 


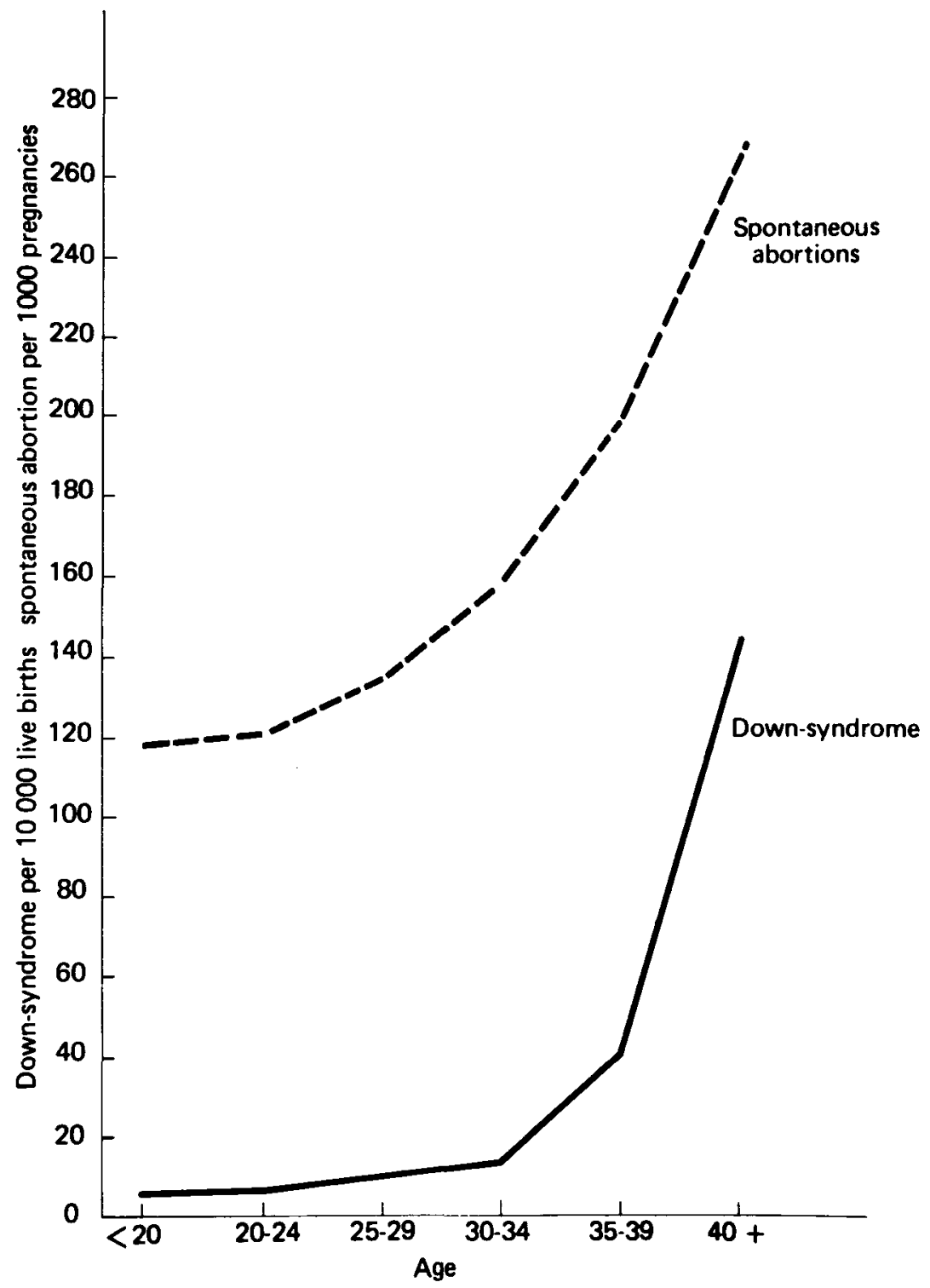

Fig. 3. The age-specific incidence of spontaneous abortion and Down-syndrome. Sources: Leridon, 1975; Hook, 1976.

Creasy et al., 1976). Also, the frequency of trisomic congenital birth defects increases markedly with age, and this is especially true of Down's syndrome (Nortman, 1974; Creasy et al., 1976; Hook, 1976). The curve of the age-specific incidence of Down's syndrome is similar in shape to the age-specific incidence of spontaneous abortion (Fig. 3).

With this background, it is possible to propose a mechanism to explain the age related increase in fetal wastage, and the age related decline in fertility prior to the 
menopause. As has been shown, a high proportion of conceptions result in fetal loss, and the majority of fetal losses occur during early pregnancy. Cytogenetic studies suggest that chromosomal abnormalities are frequently observed among spontaneous abortuses and the majority of these anomalies are trisomies. Most trisomic abnormalities probably lead to very early spontaneous abortions which are rarely observed in empirical studies, and clinically might result only in a slight delay or irregularity of the menstrual cycle. However, among those trisomic abnormalities which survive long enough to be observed in cytogenetic or clinical studies, there is a marked increase in incidence with maternal age, and this parallels the observed trend of spontaneous abortion. It is probable that the trisomic abnormalities leading to very early abortion would have a similar age pattern. Thus, the increasing frequency of trisomic abnormalities, especially those leading to abortion early in pregnancy, could account for much of the observed decline of fertility among older women.

Such a mechanism is biologically plausible since all oocytes are formed in the fetal ovary and remain in a state of arrested meiosis until ovulation. The age of the ovum derived from these oocytes is equal to the chronological age of the woman, and it is not, therefore, surprising that the frequency of chromosomal abnormalities should increase markedly with age. Many biological processes involving genetic damage have such an age related rise in incidence (Doll, 1971).

Another mechanism which might contribute to the increase in chromosomal abnormalities with age is related to the reduced frequency of intercourse among older couples. Infrequent acts of coitus are likely to increase the delay between ovulation and the deposition of spermatozoa, and this may lead to 'over-ripe gametes' which have a higher incidence of chromosomal damage (Mikamo, 1968; Lazar et al., 1973).

In summary, it would appear that the decline in fertility prior to the menopause is largely attributable to the interaction between three sets of biological or social factors: (a) an age related increase in the frequency of anovular cycles or cycles in which corpus luteum function is inadequate, (b) a reduced frequency of intercourse among older couples and (c) a marked increase in the incidence of overt or covert spontaneous fetal loss due to chromosomal abnormalities. However, these three factors cannot explain why reproduction terminates at the menopause, or why the age at menopause can vary dramatically from one population to another.

\section{Factors affecting the age at menopause and terminal reproduction}

The biological mechanism underlying the onset of the menopause is not completely understood, but ovarian failure due to depletion of oocytes appears to be the most important factor. Histological studies suggest that there is a rapid decrease in the number of oocytes shortly before the menopause, and that many of the remaining oocytes are of degenerate appearance (Jones, 1970). Endocrinological investigations show an elevation of pituitary gonadotrophins and relatively low levels of ovarian steroids prior to the menopause, which might suggest an impaired ovarian response to pituitary stimulation (Sommerville, Kitchin \& Mansfield, 1976; Reyes, Winter \& Faiman, 1977). The post-menopausal ovary is totally depleted of 
viable oocytes and is incapable of responding to pituitary stimulation (Jones, 1970; Sommerville et al., 1976).

The median age at menopause in affluent societies lies within a narrow range of 49.7 to 51.4 years, and a number of studies suggest that factors such as ethnic group, parity or marital status have very little effect upon the age at menopause (Gray, 1976). However, in developing countries the median age at menopause may be less than 44 years (Wyon et al., 1966; Scragg, 1973; Retel-Laurentin, 1977), and there is evidence to suggest that the early onset of menopause in these populations may be attributable to poor nutrition. In a New Guinean study, the median age at menopause was found to be 43.6 years among malnourished women and 47.3 years among women with more satisfactory nutrition (Scragg, 1973). Also, an American survey suggests that thin women may experience an earlier menopause (MacMahon \& Worcester, 1966) and other studies indicate that women of lower socio-economic class may reach menopause at a younger age than women of higher class (McKinlay \& McKinlay, 1973; Gray, 1976). Furthermore, some historical studies suggest that the age of menopause may have been lower among European populations during the 19th and early 20th centuries (Fromer, 1964; Hoffman \& Soergel, 1972).

There is evidence that inadequate nutrition can lead to delayed menarche and to anovulatory cycles or amenorrhoea (Frisch, 1978), so it is biologically plausible that inadequate nutrition could lead to premature menopause. This clearly could influence both the level of total ferility and the need for contraception among older women in less affluent populations since premature occurrence of the menopause could markedly limit the potential reproductive lifespan.

\section{Discussion}

Roberts: One of the things that has impressed me as a result of today's presentations is the expression of surprise that fertility diminishes with age. This is partly due to the fact that some demographers and others concerned with fertility have been males. To me it is not at all surprising when we consider the trauma of the reproductive process and I am sure that many of my obstetric colleagues would agree. There are the problems of retained products of conception after miscarriage, of materno-fetal immunization, of congenital inadequacies, of cervical incompetence particularly after mismanaged labours, the fundamental problems of fibroids and many other similar things, of which women are so aware, and of which the mere male may not appreciate the significance. Second, there is the age influence, particularly in women, on the increasing incidence of autoimmune disease which, for instance in thyroid disorders, may upset reproductive control, endocrine balance and so on. Third, a most important biosocial feature of diminishing fertility which has not been mentioned is the effect of veneral disease. Our work in East Africa 20 or 25 years ago suggested that a large proportion of reduced fertility there was due to widespread occurrence of veneral disease.

There are thus these other factors, both intrinsic and biosocial, which should be borne in mind without, of course, decrying the importance of those discussed by $\mathrm{Dr}$ Gray. 
Gray: I agree entirely with Professor Roberts about what might be called medical cost of reproduction in the later age groups.

I should like to take up the point of venereal disease, which from the data that I have obtained from Africa and elsewhere, is not a problem restricted to the older age groups. If women get gonorrhoea and subsequently become infertile because of tubular blockage, it tends to occur quite early. With syphilis, the associated infertility is self-limited to the primary and secondary stages, during which there is a high risk of stillbirths and fetal wastage. I would not therefore agree with Professor Roberts that infertility due to venereal disease could be a major factor in determining the declining fertility at later ages, although it is a major factor in determining the overall prevalence of infertility.

Roberts: But venereal disease is age-related in communities with absentee males, where the likelihood of their bringing back venereal disease may increase the longer they are away from home.

D. T. Baird: Dr Gray referred several times to the relationship between nutrition and the age of menopause. This is important because there is a correlation between nutritional status and the incidence for example, of spontaneous amenorrhoea and the length of lactational amenorrhoea. In a population in which a significant number of the women are under-nourished some women will experience a prolonged period of nutritional or lactational amenorrhoea which will extend into the natural menopause. It will be difficult in those circumstances to determine exactly when the onset of the last spontaneous menstrual period occurs. The experimental evidence on rats shows that depletion of the number of oocytes is almost impossible to achieve with any manipulation. Whether they are fat or thin, the rate of atresia or the rate at which oocytes are depleted from the ovary is unchanged. I doubt whether nutritional status alters the rate at which the number of oocytes are depleted from the ovary, it merely alters the manifestation of when the last menstrual period occurs.

Gray: I was not postulating what might be called a cellular mechanism for the way in which nutrition might affect the age at menopause. I would speculate that it works through endocrinological mechanisms. With lactation, there are a number of studies to show that it does not appear to be the mother's nutrition which prolongs the lactational amenorrhoea so much as the intensity of nipple stimulation among poorly nourished women in most of these countries that seems to prolong their amenorrhoea. They are often in the lower social classes and cannot afford supplements.

I do not know whether lactational amenorrhoea extends into menopausal amenorrhoea. It may be a reason why ages at menopause are apparently earlier in historical or developing country populations. It is known that women will become amenorrhoeic if they are malnourished, and subsequently resume cycling if they are well nourished again. It is plausible to argue that if women are nutritionally depleted they are more likely to have earlier terminal amenorrhoea and to remain in that state past the menopause or until nutritionally repleted.

Van Keep: I heard that Polish women who spent 4 or 5 years in concentration camps had a later natural menopause. It would be interesting to know if women who have had long periods of amenorrhoea due to anorexia nervosa have a later 
menopause, since, according to Jones and Krohn (1959, 1961, cited by Jones, 1975 ) in mice the rate of oocyte decline decreases after hypophysectomy and also by severe restriction of calory intake (Huseby \& Ball, 1945). I wonder if a parallel can be made in man?

Why do well-nourished women tend to have a later menopause? I think that an explanation could be, found in the higher peripheral production of oestrone and oestradiol. If the cyclical production of oestrogens by the ovaries diminishes, it will depend upon the peripheral production of oestrogens at what moment the total amount of oestrogen present in the body is insufficient to stimulate the endometrium.

Gray: That could well be so. With respect to anorexia nervosa, anorectics do not have a later menopause but rather to the contrary, they tend to have prolonged amenorrhoea. If they are in their 40 s when they have this amenorrhoea they are usually assumed to be menopausal. If I understood you correctly, you were implying that the anorectics had a late menopause?

Van Keep: That is what I would presume, on the basis of the data for mice.

Gray: I think we are dealing here with a quite different set of circumstances. This is nutritional deprivation throughout life which delays puberty. It seems to be something which can be turned off and on. In rats, if the animal's nutrition is supplemented late in life, it is possible for it to go into oestrus. This is possibly true in humans; for example, during the famine in Holland during World War II it was clearly shown that menstrual cycles can be resumed after malnutrition is reversed.

$D$. T. Baird: Is Dr Van Keep saying that by starving the mice the rate at which they lose their primary oocytes can be changed?

Van Keep: Yes, I am quoting Esther Jones.

D. T. Baird: It seems unlikely that nutritional status would alter the age of ovarian failure. While it is true in mice that following starvation there is a change in the proportion of atretic and non-atretic Graafian follicles, there is no change in the total number of oocytes (Huseby \& Ball, 1945). As the eventual life span of the ovary depends on the number of primary oocytes present, it is apparent that this treatment will not alter the time of onset of ovarian failure.

Van Keep: I will check these facts.

Brass: (intervening) There is a set of experiments of that kind, but the relationship between that and the human experience is uncertain.

Gray: My impression is the same as Professor Baird's, that it is not a cellular change.

D. Baird: It is well recognized, other things being equal, that good health and physique increase life expectancy. Age at the menarche has fallen as the level of health and development of children has risen.The age at the menopause has risen for the same reason. The incidence of low birth weight ( $2500 \mathrm{~g}$ or less) whether as a result of short gestation or retarded intrauterine growth increases steadily with decreasing social status. In New York State, for example, the incidence of low birth weight (LBW) was lower in farmers and highest in labourers (Table 3). The lower the overall rate the longer the inevitable rise in the rate with increasing age was delayed - for example, till the 35-39 age group in farmers' wives. This was 5 years later than in the professional group and possibly due to some extent to a uniformly 
higher level of physique and health in farmers' wives resulting from optimal socioeconomic conditions in childhood and adolescence.

The perinatal mortality rate associated with 'unexplained' LBW and malformations of the central nervous system is very high in unskilled manual occupational groups in large industries in the UK and is related to the very depressed socioeconomic conditions existing at the time of the mother's birth. Rates are particularly high in the women born between 1928 and 1934 when unemployment rates were very high. Women with the highest rates from these causes tended to have large families but their fertility, as defined by their ability to

Table 3. Per cent low birth weight infants ( $2500 \mathrm{~g}$ or less) by father's occupation and mother's age, New York State*, 1950-52 live-birth cohort

\begin{tabular}{|c|c|c|c|c|c|c|c|}
\hline \multirow[b]{2}{*}{ Father's occupation } & \multirow[b]{2}{*}{ Total } & \multicolumn{6}{|c|}{ Mother's age (years) } \\
\hline & & $<20$ & $20-24$ & $25-29$ & $30-34$ & $35-39$ & $40+$ \\
\hline Labourers & $8 \cdot 1$ & $9 \cdot 2$ & $7 \cdot 8$ & $7 \cdot 1$ & $8 \cdot 7$ & $9 \cdot 3$ & $10 \cdot 7$ \\
\hline Craftsmen & $7 \cdot 1$ & $8 \cdot 1$ & $6 \cdot 9$ & $6 \cdot 7$ & $7 \cdot 1$ & $8 \cdot 1$ & 9.9 \\
\hline Professional & $6 \cdot 1$ & $7 \cdot 4$ & $5 \cdot 7$ & $5 \cdot 7$ & $6 \cdot 3$ & $7 \cdot 8$ & 9.4 \\
\hline Farmers & $6 \cdot 0$ & $7 \cdot 5$ & $5 \cdot 8$ & $5 \cdot 7$ & $5 \cdot 5$ & $6 \cdot 5$ & $8 \cdot 2$ \\
\hline
\end{tabular}

Source: Chase (1962).

* Excluding New York city.

produce well-grown and healthy children, is relatively poor, especially over the age of 30 . The high rates are mostly from causes not amenable to prevention by a high standard of obstetric care.

Greep: The Harvard School of Public Health has produced some data recently showing that the consumption of alcohol during pregnancy results in low weight babies and an increase in birth defects. Also, smoking is reported to be deleterious in pregnancy. These are practices a farm woman would not be likely to abuse. As a matter of fact, farm women are very well nourished and seldom smoke or drink to any large extent.

Gray: The Indian researchers have done a considerable amount of work over the past 20 years which shows clearly the effect of poor maternal nutritional status on low birth weight of their infants (Belavady, 1969).

Sir Dugald said he felt that it was lifetime maternal depletion. There was a study done in the 1960s in the heyday of nutritional supplements which showed that supplementing the women's diet during pregnancy did not appear to affect the probability of low birth weight infants. It may be that it is nutritional deprivation throughout life that is the important factor.

D. Baird: The stillbirth rate fell by $30 \%$ during the war years probably as a result of the Government's enlightened food rationing policy. It could be shown that a substantial fall in the death rate in the first week of life associated with low birth weight occurred during the war years but no reliable information on changes in the 
incidence of low birth weight is available. The fact that there was no further fall in the stillbirth rate from 1948 to 1957 raised the possibility that the benefits derived from improved diets during the actual pregnancy had been largely exhausted.

Thomson: I know of no evidence that malnutrition at a level short of starvation is associated with diminished fertility. In fact, it is notorious that the worstnourished, but not starving, communities of the world have the highest birth rates, other things being equal, which of course they never are.

To return to the question of the menopause, there seems to be an extremely narrow range of differences in mean age of menopause. Dr Gray was talking in terms of something like 47 years and 44 years in his two groups in New Guinea-a 3-year difference. I am not sure that makes a great deal of difference to fertility estimates, or whether it is very important. There are extremely wide ranges around the world of nutritional status, using that term in its broadest possible sense. It seems to me that those ranges can explain, at best, only a very narrow range of variation in menopausal age. I am not sure that this subject is worth pursuing.

Brass: There is a recent rigorous and sophisticated study about to be published by Bongaarts \& Delgado of Guatemalan data which showed no nutritional effects on fertility at the individual level. The evidence Dr Gray is quoting is rather dangerous because it is group, not individual, measurements. It may be that the remarkable highland community of New Guinea, with age of menarche over 18 years and age of menopause around 43 years, is so different from the normal that we are arguing from a very special case.

Gray: I, too, am surprised that there can be a wide variation in the age of menarche from 11 to more than 18 years, whereas the age of menopause seems to vary between 44 and 51 years. There seems to be a narrower range for age at menopause than for age at menarche.

Sherman: I am not sure that it is possible to compare the narrow range of the age at menopause with what happens at menarche. The process of atresia in the ovary goes on from the time of fetal life, when there are millions of ova which are reduced quite markedly by the time that puberty occurs, and which continue to be reduced thereafter. This process probably determines the age of menopause, and not that there are perhaps a certain total number of ovulations. Ovulation could probably be induced in a pre-menarchal girl by giving her exogenous gonadotrophins; the ovary is quite passive in that sense. The process which occurs at menopause, about which we know little, is the process of atresia.

Gray: We have to differentiate here between the distribution of the ages at menopause or menarche recorded in a population and the difference in the mean or median ages of menopause or menarche, which are observed in different populations. The distribution of the age of menopause is much wider than the distribution of the age of menarche in any given population, and the standard deviation of the mean age at menopause is much greater than for the age of menarche. But the variations in the mean ages for menarche around the world are much greater than variations in the mean ages for menopause.

The altitude these New Guinea highland people live at is about $400-500$ feet. The other group, with the median age of menopause of 47 plus, was coastal. There is no evidence that I know of, from Andean populations for example, that altitude affects menopause. 
Flint: Charles Hoff (1968) quotes Cruz-Coke as finding menopause age in women at high altitudes to be just over 3 years earlier. It is conjectured that hypoxia is a cause of earlier age of menopause in the Altiplano population of Peru.

Leridon: On another point, that of fetal wastage and fecundability, the last graph shown by Dr Gray exhibited an increase in the rate of fetal wastage with age from about $12 \%$ to $27-28 \%$. This is what we call 'apparent' intrauterine mortality. The rate recorded is achieved by asking women how many pregnancies they have had which have ended in other than a live birth, or by getting the figures of spontaneous abortions from hospitals. There is good evidence, by means of life-table techniques, that the actual rate of pregnancy wastage, starting from the first missed period (which means 2 weeks' development of the pregnancy) could be as high as $25 \%$, even though the 'apparent' rate would be 10-15\%.

Dr Gray mentioned too that there must also be a high proportion of fetal wastage before that stage (two weeks' development) which is unrecorded and difficult to detect, even by sophisticated means.

I do not know which of these various components are related to age. What we see with apparent intrauterine mortality is the last part of the story, obviously. There is evidence that some of the chromosomal abnormalities responsible for early abortions increase with age, but not all of them. Now if a mean apparent rate of $12-15 \%$ corresponds to an actual rate of $50 \%$ or more, at older ages-when the mean apparent rate is higher than 25\%-there might be more than $100 \%$ conceptions ending in spontaneous abortion! That would mean either that we have here the whole explanation for the decrease in fecundity with age, or that not all parts of intrauterine mortality increase with age by the same pattern.

Finally, on the relationship of the frequency of intercourse with the fecundability of the cycle, Dr Gray mentioned the study by Barrett \& Marshall which is a very important one. Dr Schwartz in Paris is using the same data with a slightly different model. In the original model the daily probabilities were computed assuming that the risks of conception from different acts of coitus within the same cycle are statistically independent. Dr Schwartz and colleagues have a slightly different model starting from the assumption-or the idea - that to come out with a recognizable pregnancy there has to be, first, an ovulation during the cycle, second, fertilization and third, an egg which is sufficiently good to live for at least 2 weeks. It is only the second of those three which is really dependent on the frequency of intercourse, since the probability of having an ovulation and the probability of having a good egg are both independent of it. This model leads to approximately the same daily probabilities of conceiving; but when there are two, three or four intercourses during one week, this does not increase the total fecundability of the cycle as rapidly as when the previous model is used. In their preliminary conclusions, the authors are very cautious but say that perhaps $50 \%$ of ovulations are not capable of being fertilized or of producing a viable egg.

These findings would support the idea that there is probably not a directly proportional relationship between the frequency of intercourse and fecundability of the cycle.

Brass: I think that is true. This particular model is one which Dr Gray and I have discussed, and we came to about the same conclusions, even though we put different weight on particular aspects. My own work in this field was an attempt to use 
frequency of intercourse data, together with length of time to conception for women who were of established fertility, because they had had a child recently (data from Cartwright, 1976) to see whether there was much fall in the probabilities of conception. The conclusion was that there was practically none, when frequency of intercourse was allowed for. It should be remembered, however, that we are dealing with a group of women at later reproductive ages who are still fertile and have regular menstrual cycles. Because of this, the findings may simply mean that there are some women in their late 30 s and early 40 s who behave, with respect to probabilities of conception, in much the same way as women in their 20s. It does not answer the question of how big a proportion these women are of their whole age group.

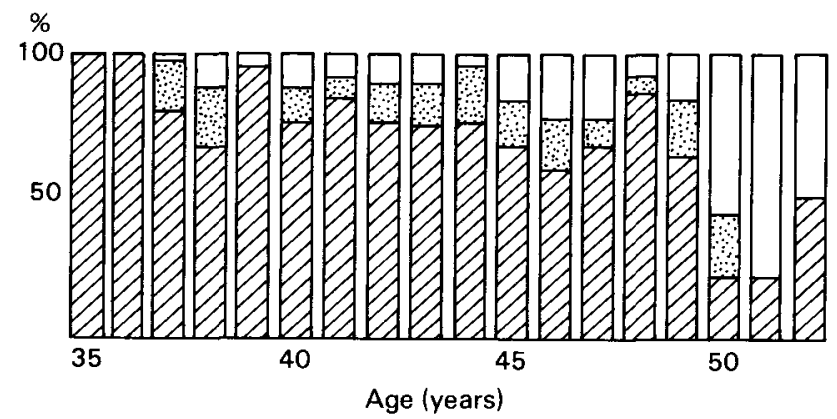

Fig. 4. Classification of menstrual cycles in women aged over 35 , by basal body temperature: $\square$, biphasic cycles; 囬, cycles with luteal insufficiency; $\square$, monophasic cycles.

It remains true that the clearest evidence of a determining factor that changes greatly with age is frequency of intercourse. If that frequency decreases by $50 \%$, as it does at these late ages, and if there is not quite proportionality, but nevertheless a strong relationship between frequency of intercourse and fecundity, this has a powerful effect on fertility.

The changes in the frequency of intercourse do not seem to me to be greatly associated with social pressures of the kinds about which we have talked. They seem to depend on length of marriage and the way that most couples behave in most societies. Therefore, there is what might be called a natural social factor involved as well as a natural biological factor.

Gray: With regard to the first part of Dr Leridon's statement (p. 111) life table techniques on the French and German data show that about $24 \%$ of conceptions will perish between the fourth week and full term. If an extrapolation is made back to the embryological data it is possible to estimate that in toto about half of all zygotes will perish. These data are total figures and are not standardized for age. Leridon: I do not know of any good life table type estimates of the probability of fetal wastage by age.

Gray: Shapiro's data are probably the best that give a breakdown by age, which is why I used them. We should look at the shape of the curve, especially at the proportional increase in fetal wastage between ages 30 and 40 plus. Dr Leridon's 
suggestion that, at a certain age, there is $100 \%$ fetal wastage is perhaps not treating these data correctly. There is probably a base line level of fetal wastage, upon which some forms of fetal wastage, perhaps the trisomies, increase with age. We can talk only about the general level and the shape of the curve. If there were more precise information then one could try to produce a model, but I gave up that idea because of lack of empirical data.

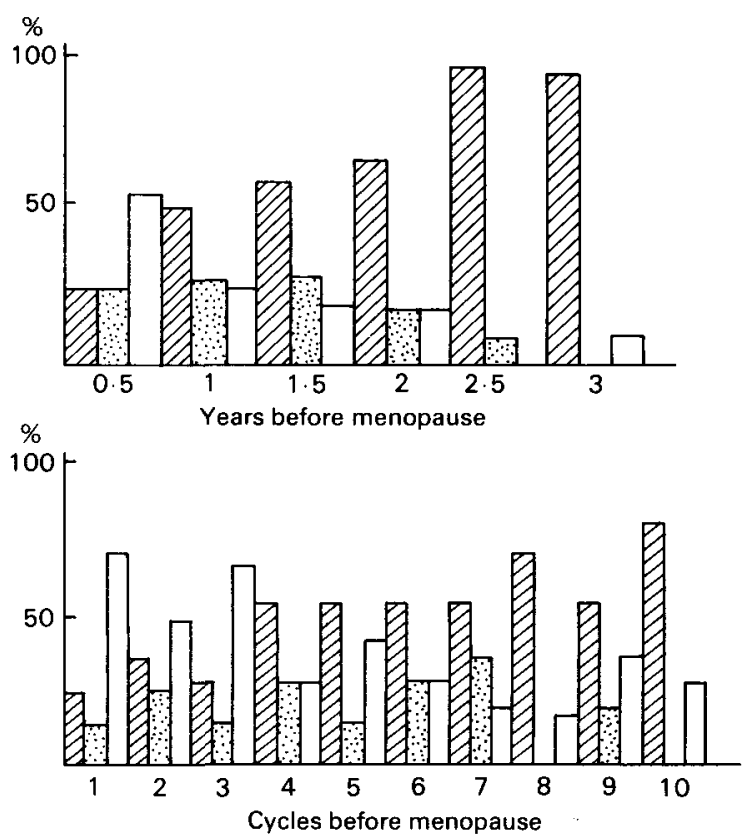

Fig. 5. Premenopausal menstrual cycles observed by basal body temperature: symbols as in Fig. 4.

Matsumoto: The results of classifying menstrual cycles in women aged over 35 by measuring basal body temperature changes (Fig. 4) show that there is a decrease in the number of ovulatory cycles and an increase in anovulatory cycles in women after about 45 years old, and especially after 50 years of age. This is also shown, especially in the 2 years before menopause, in our analysis of 201 premenopausal cycles in which the basal body temperature was recorded until menopause (Fig. 5.). The majority of the three cycles before menopause are anovulatory.

\section{References}

Alberman, E. \& Creasy, M.R. (1975) Factors affecting chromosome abnormalities in human conceptions. In: Chromosome Variations in Human Evolution, p. 88. Edited by A. J. Boyes. Taylor \& Francis, London.

ANDERson, B.A. (1975) Male age and fertility; results from Ireland prior to 1911. Popul. Ind. 41, 561. 
Barclay, G.W., Coale, A.J., Stoto, M.A. \& Trussel, T.J. (1976) A re-assessment of the demography of traditional rural China. Popul. Ind. 42, 606.

BARRETT, J.C. \& MARShaLl, J. (1969) The risk of conception on different days of the menstrual cycle. Popul. Stud. 23, 455.

BELAVADY, B. (1969) Nutrition in pregnancy and lactation. Ind. J. med. Res. 57, 63.

BisHop, M.W.H. (1970) Ageing and reproduction in the male. J. Reprod. Fert. Suppl. 12, 65.

Caldwell, J.C. \& CAldwell, P. (1977) The role of sexual abstinence in determining fertility: a study of the Yoruba in Nigeria. Popul. Stud. $31,193$.

Cartwright, A. (1976) How Many Children? Routledge \& Kegan Paul, London.

Chase, H.C. (1962) The Relationship of Certain Biological and Socio-economic Factors to Fetal, Infant and Early Childhood Mortality. New York State Department of Health.

Chen, L.C., Ahmed, S., Gesche, M. \& Mosley, W.H. (1974) A prospective study of birth interval dynamics in rural Bangladesh. Popul. Stud. 28, 277.

Chiazze, L., Brayer, F.T., Macisco, J.J., Parker, M.P. \& Duffy, B.J. (1968) The length and variability of the human menstrual cycle.J.Am. med. Ass. 20, 377.

CoAle, A.J. \& Trussel, T.J. (1974) Model fertility schedules: variations in the age structure of childbearing in human populations. Popul. Ind. 40, 185.

Creasy, M.R., Crolla, J.A. \& Alberman, E.D. (1976) A cytogenetic study of human spontaneous abortion using banding techniques. Hum. Genet. 31, 177.

DoLl, R. (1971) The age distribution of cancer: implications for models of carcinogenesis. J.R. statist. Soc. 134, 133.

DoRING, G.K. (1969) The incidence of anovular cycles in women. J. Reprod. Fert. Suppl. 6, 77.

French, F.E. \& Bierman, J.M. (1962) Probabilities of foetal mortality. Publ. Hlth Rep. 77, 835.

Frere, G. (1971) Mean age at menopause and menarche in South Africa. S. Afr. J. med. Sci. 6, 21.

FrisCH, R.E. (1978) Population, food intake and fertility. Science, N.Y. 199, 22.

Fromer, D.J. (1964) Changing age of menopause. Br. med. J. 2, 349.

GrAY, R.H. (1976) The menopause: epidemiological and demographic considerations. In: The Menopause, p. 25. Edited by R. J. Beard. MTP, Lancaster.

HENRY, L. (1961) Some data on natural fertility. Eugen. Q. 8, 81 .

HoFF, C.J. (1968) Reproduction and Viability in a Highland Peruvian Population in High Altitude Adaptation in a Peruvian Community. Occasional Papers in Anthropology No. 1. Department of Anthropology, Pennsylvania State University.

Hoffman, D. \& SoErgel, T. (1972) Studies on the age of menarche and the age of menopause. Geburtsch. Frauenheilk. 32, 969.

Hook, E.B. (1976) Estimates of maternal age-specific risks of a Downs-syndrome birth in women aged 34-41. Lancet, ii, 33.

HUSEBY, R.A. \& BALL, Z.B. (1945) A study into the genesis of histological changes produced by caloric restriction in portions of the endocrine and reproductive systems of strain $A$ female mice. Anat. Rec. 92, 135.

Jain, A.K., Hsu, T.C., Freedman, R. \& Chang, M.C. (1970) Demographic aspects of lactation and post-partum amenorrhoea. Demography, 7, 255.

James, W.H. (1970) The incidence of spontaneous abortion. Popul. Stud. 24, 241.

JONES, E.C. (1970) The ageing ovary and its influence on reproductive capacity. J. Reprod. Fert. Suppl. 12, 17.

JONES, E.C. (1975) The post-reproductive phase in mammals. In: Estrogens in the Postmenopause, p. 1. Frontiers in Hormone Research, Vol. 3. Edited by P. A. Van Keep \& C. Lauritzen. Karger, Basel.

Kinsey, A.C., Pomeroy, M.B. \& Martin, C.E. (1953) Sexual Behaviour in the Human Male. Saunders, Philadelphia.

KNODEL, J. (1978) Natural fertility in pre-industrial Germany. Popul. Stud. 32, 481. 
Lazar, P., Gueguen, S.. Boue, J. \& Boue. A. (1973) Epidémiologie des avortements spontanes precoces: à propos de 1,409 avortements caryotypes. In: Chromosomal Errors in Relation to Reproductive Failure, p. 317. Edited by A. Boué \& I. Thibault. Proceedings of the Symposia sponsored by INSERM, DJRST and OMS. Centre International de l'Enfants, Paris.

LERIDON, H. (1975) Biostatistics of human reproduction. In: Measuring the Effects of Family Planning Programmes on Fertility, p. 93. Edited by B. Chandrasekaran \& A. I. Hermalin. Ordina Editions, Belgium.

MacMahon, B. \& Worcester, J. (1966) Age at Menopause: United States 1960-1961. Vital Health Statistics, Series II, 19. US Department of Health, Education and Welfare, Washington, DC.

Masters, W.H. \& Johnson, V.E. (1966) Human Sexual Response. Churchill, London.

McKinlay, S.M. \& McKinlay, J.B. (1973) Selected studies of the menopause. J. biosoc. Sci. 5, 533.

McKusick, V.A. (1964) Human Genetics. Prentice-Hall, New Jersey.

Мıкамо, K. (1968) Intra-follicular over-ripeness and teratogenic development. Cytogenetics, 7, 212.

NaG, M. (1972) Sex, culture and human fertility: India and the United States. Curr. Anthropol. 13, 231.

NAYLOR, A.F. (1974) Sequential aspects of spontaneous abortions: maternal age, parity and pregnancy compensation artifact. Soc. Biol. 21, 195.

Nortman, D. (1974) Parental age as a factor in pregnancy outcome and child development. Rep. Popul. Fam. Plann. 16, 37.

Pittenger, D.B. (1973) An exponential model of female sterility. Demography, 10, 113.

Potter, R.G. (1963) Birth intervals: structure and change. Popul. Stud. 17, 155.

Reyes, F.I., Winter, J.S.D. \& Faiman, C. (1977) Pituitary-ovarian relationships preceding the menopause. A cross-sectional study of $\mathrm{FSH}, \mathrm{LH}$, prolactin, estradiol and progesterone levels. Am.J. Obstet. Gynec. 129, 557.

SCRAGG, R.F.R. (1973) Menopause and reproductive life-span in rural New Guinea. In: Annual Symposium of the Papua in New Guinea Medical Society, p. 126. Public Health Department, Port Moresby, Papua New Guinea.

Shapiro, S., Levine, H.S. \& ABramowicz, Z. (1970) Factors associated with early and late foetal loss. In: Advances in Planned Parenthood, Vol. VI, p. 45. Proceedings of the VIIIth American Association of Planned Parenthood Physicians Meeting. Excerpta Medica, Amsterdam.

Sommerville, I.F., Kitchin, Y. \& MANSFIELD, M.D. (1976) Endocrine changes at the menopause. In: The Menopause, p. 41. Edited by R. J. Beard. MTP, Lancaster.

TALBERT, G.B. (1968) Effect of maternal age on reproductive capacity. Am. J. Obstet. Gynec. 102, 451.

ThOmpson, B., HART, S.A. \& DuRno, D. (1973) Menopausal age and symptomatology in a general practice. J. biosoc. Sci. 5, 71.

TIETZE, C. (1957) Reproductive span and rate of reproduction among Hutterite women. Fert. Steril. 8, 89.

Treloar, A.E., Boynton, R.E., Behn, B.J. \& Brown, B.W. (1967) Variation of the human menstrual cycle through reproductive life. Int. J. Fert. 12, 77.

Vollman, R.F. (1977) The Menstrual Cycle. Saunders, Philadelphia.

Wright, E.V. (1976) Chromosomes and human fetal development. In: The Biology of Human Fetal Growth, p. 237. Edited by D. F. Roberts and A. M. Thomson. Taylor \& Francis. London.

Wyon, J.B., FinNer, S.L. \& Gordon, J.E. (1966) Differential age at menopause in rural Punjab, India. Popul. Ind. 32, 328. 